\title{
50 Years of 10 December 1967 M 6.3 Koyna Earthquake
}

\section{Preface}

Artificial water reservoirs are created globally for irrigation, flood control and power generation. Reservoir Triggered Seismicity (RTS) is an anthropogenic effect of creating artificial water reservoirs. Under certain suitable geological conditions, filling of a reservoir can trigger earthquakes. The first scientifically accepted case of RTS is from Lake Mead in USA in the 1930's. Over the years some 120 sites have been globally identified having RTS. Damaging earthquakes exceeding M 6 have occurred at Hsingfengkinag, China; at Kariba on Zambia-Zimbabwe border; Kremasta, Greece and at Koyna, India. The M 6.3 Koyna earthquake of December 10, 1967 is so far the largest RTS event globally. It claimed $\sim 200$ human lives. The Koyna town-ship was in shambles. At the National Geophysical Research Institute (NGRI), Hyderabad, a seismological observatory, with instrumentation identical to the World Wide Standard Seismograph Network (WSSN) had been set up. It was commissioned on the morning of $11^{\text {th }}$ December 1967 to record the aftershocks of the Koyna earthquake. A detailed field survey was conducted where Dr. Hari Narain, the then Director of NGRI, took part. Several very interesting observations were made, including documenting evidences of rotational displacement on a pillar at Donachiwadi. Incidentally, the first paper in Nature from NGRI was on Koyna Earthquake in 1968. Detailed analyses of the seismograms obtained from all over the world, and by picking up arrivals of P phases, the Koyna earthquake was identified to be a multiple seismic event and the direction of propagation of rupture and the length of faulting was inferred using Gutenberg sine-curve plots. By 1970's over a dozen cases of RTS were known from all over the world. A systematic study of RTS sequences at these sites revealed their certain common characteristics that differentiated them from normal earthquake sequences in the concerned regions. These characteristics are consistently found in the later RTS sequences, and are also useful to ascertain whether earthquakes occurring in the vicinity of an artificial reservoir are triggered or normal (not triggered by the reservoir). Unlike the other RTS sites, where triggered earthquakes ceased to occur in a few years to a decade's time, RTS has continued at Koyna till now. Although a clear correspondence has been demonstrated in several reservoir loading parameters such as the rate of loading, highest water levels reached, duration of retention of high water levels and the fact whether the previous water maxima in the reservoir has been exceeded or not and RTS at Koyna, the exact role played by the reservoir in triggering the earthquakes is still not clear. As a matter of fact, we know precious little about physical properties of rocks and fluids in the fault zone and their role in triggering earthquakes for extended period due to lack of near field observations. As of now 22 earthquakes of $M \geq 5.0$, and over 200 earthquakes of $\mathrm{M} \geq 4.0$ and several thousand smaller earthquakes have occurred in the region. The question of setting a borehole observatory to investigate triggered earthquakes was discussed in two International Continental Drilling Program (ICDP) Workshops in 2011 and 2014. These workshops very strongly supported setting up of a borehole laboratory. A unique network of 6 closely spaced 3 component seismic stations at a depth of $\sim 1500 \mathrm{~m}$ has been set up in the region to improve earthquake locations.

Over the years, more than 200 scientific papers, several dedicated volumes on RTS, two books and two articles in encyclopedias have appeared, with special emphasis on Koyna. The Council of the Geological Society of India thought it appropriate to dedicate the December, 2017 issue of the Journal of the Geological Society of India to address developments over the last 50 years on Koyna RTS. Several scientists were invited to contribute and an advertisement was also made in the Journal soliciting contributions to the December 2017 issue. In this special issue of the journal 25 of the papers accepted for publication are included.

In sequencing these papers, an effort is made to first introduce Koyna RTS ( $1^{\text {st }}$ article), give geological background ( $2^{\text {nd }}$ article $)$; cover geophysical work ( $3^{\text {rd }}$ to $11^{\text {th }}$ articles); geological field investigations ( $12^{\text {th }}$ to $16^{\text {th }}$ articles); studies on the cores obtained from the boreholes in the Koyna-Warna region ( $17^{\text {th }}$ to $22^{\text {nd }}$ articles $)$; setting up laboratory facilities ( $23^{\text {rd }}$ article); and the last two papers deal with most recent seismic activity in the Koyna-Warna region $\left(24^{\text {th }}\right.$ article $)$ and Koyna reservoir loading/unloading parameters and RTS ( $25^{\text {th }}$ article).

To start with, Gupta has made a case for the suitability of the Koyna region for near field study of earthquakes. Before the impoundment of the Shivaji Sagar Lake created by the Koyna Dam, there were no earthquakes reported from the region. Initially a few stations were operated in the region by the Central Water and Power Research Station (CWPRS). The seismic station network grew with time and currently the National Geophysical Research Institute (NGRI), Hyderabad is operating 23 broadband seismographs and 6 bore hole seismic stations in addition to the seismic stations operated by other agencies (such as India Meteorological Department, Central Water and Power Station). Another reservoir, Warna, was created in 1985, which provided a further impetus to RTS. Every year, following the monsoon, water levels rise in the two reservoirs and there is an immediate increase in triggered earthquakes in the vicinity of KoynaWarna reservoirs in the months of August - September. Peak RTS is observed in September and later during December. Another spurt in triggered earthquakes is observed during the draining of the reservoirs in the months of April-May. A comparative study of RTS sequences and the ones occurring in nearby regions made it possible to identify four common characteristics of RTS sequences that discriminate them from normal earthquake sequences. As the RTS events continue to occur at Koyna in a large number in a limited area of $20 \mathrm{~km}$ x $30 \mathrm{~km}$, at shallow depths, it was thought to be an ideal site for near field observations of earthquakes. This was discussed by the global scientific community at an ICDP sponsored workshop held at Hyderabad and Koyna in 2011. There was a unanimous agreement about the suitability of the site for deep scientific drilling; however, a few additional observations/experiments were found to be necessary before taking up deep borehole drilling. These were carried out in the following three years and another ICDP workshop was held in 2014, which totally supported setting up a borehole laboratory for near field investigations at Koyna. Location of a Pilot Bore-hole was decided on the basis of seismic activity and other logistics. The $3 \mathrm{~km}$ deep Pilot Borehole was spudded on December 20, 2016 and completed on June 11, 2017.

In an interesting paper, Subbarao and Courtillot review the magnetostratigraphy of the Deccan Traps, particularly in the Western Province. They compare geomorphological and Koyna borehole data with the earlier known regional structural data. Koyna and Warna 
region comprises of chemically defined younger Formations of Wai Subgroup and Lonawala Subgroup displaying over-stepping arrangement from older Formations further north in the Nasik area and younger Formations down south. This is further corroborated by a single polarity change from reversed to normal, all the way to Belgaum. This is considered as a time marker around 65Ma (Chron C29r /C29n) matching with the K-T boundary. The Deccan Trap contact with the Archean basement in the 7 boreholes shows a plateau around $200 \mathrm{~m}$ in the western section but a variation ranging up to $500 \mathrm{~m}$ in the eastern side of the Warna region. They believe that a combination of surface and sub-surface data of the Koyna-Warna region may not show the presence of older volcanic formations such as Kalsubai Subgroup nor ages older than $65 \mathrm{Ma}$.

Sarkar and Sain have examined the two East-West running seismic reflection profiles: (1) just south of the Koyna Dam and (2) some $50 \mathrm{~km}$ north of the Koyna Dam. These profiles were made during December 1977 through March 1978. They have provided useful information on shallow crustal structure of the region. A quick look at the profile \# 1, running just south of the Koyna Dam (Figure 2), shows the SP 50 (shot point 50) lying very close to the Donachiwada Fault, which hosted the December 10, 1967 earthquake and several other $\mathrm{M} \sim 5$ earthquakes. One could see the signatures of Donachiwada Fault on this section.

Arora, Chadha, Srinu, Selles, Srinagesh, Smirnov, Ponomarev and Mikhailov have presented the results of first airborne LiDAR survey flown over the Koyna-Warna region, developed a bare earth model for the region and have addressed the relation between lineament fabric and ongoing seismicity. Seismicity peaks during loading and unloading phases have been also identified. They underline a new peak of seismicity occurring during March-April consequent to loading of the Warna Reservoir in 1985. A much-required list of $M \geq 4$ earthquakes in the Koyna-Warna region has been also provided.

Kuempel, Chadha, Ramana and Ravi have investigated in-situ pore pressure variations in the Koyna-Warna region by deploying sensors in 21 shallow bore holes under an Indo-German research program during 1995-1998. Tidal signals were observed in most of the wells indicating sensitivity to small strain changes in hydraulically connected, confined aquifers. These signals could be used to infer local stress field variations. Distinct co-seismic step-like changes corresponding with earthquakes of M 4.0 to 5.3 in the region are observed. The wells which respond to earth tides are favorable for the detection of weak pore pressure anomalies induced by the reservoirs or by changes in crustal stress, and hence such wells can be considered as volume strainmeters of resolution of the order 10 nanostrain or better. Monitoring pore pressure changes in the newly drilled deep bore wells in KoynaWarna region is highly promising in revealing unique insight into the variable in-situ stress-strain regime allowing RTS to occur for more than five decades here.

Purnachandra Rao and Shashidhar have carried out a detailed study of focal mechanism of earthquakes occurring in the Koyna-Warna region and compiled solutions for $50 \mathrm{M} \sim 4$ earthquakes. Strike-slip is the dominant mechanism with a few showing normal faulting in the vicinity of Warna Reservoir. Recent studies based on modeling of seismic broadband waveform data provided accurate focal mechanisms with unprecedented location accuracies including focal depths. They have inferred a periodic variation of stress field alternating between strike-slip and normal faulting in the Koyna-Warna region.

Kumar and Dixit have determined 3-D velocity structure in the Koyna-Warna region using the data from a dense network of 97 seismic stations operated in the region for the period January to May 2010. They used the data from 400 earthquakes of $\mathrm{M}<4$ and inverted $7826 \mathrm{P}$ - and $7047 \mathrm{~S}-\mathrm{P}$ arrival times for 3-D Vp and Vp/Vs tomographic models along with hypocenters parameters in the region. High $\mathrm{Vp}$ ( $\sim 5.9$ to $6.5 \mathrm{~km} / \mathrm{s})$ and low to high $\mathrm{Vp} / \mathrm{Vs}$ ratio (1.69-1.74) is imaged in the hypocenter region. These features are interpreted as fluid bearing rock mass under high pore pressure. They observed a local topography depression between the Koyna and Warna reservoirs below the trap basement.

Rastogi has written about pore pressure diffusion in the KoynaWarna region, migration of seismicity and short term earthquake forecasts based on observing nucleation that precede $M>4$ earthquakes. He reports that the continued triggered seismicity in Koyna region is found to migrate southward. The continued seismicity seems to be controlled by permeable critically stressed fault zones. Nucleation of small events precedes $M>4$ earthquakes near Warna Reservoir. Success has been achieved in making short-term earthquake forecasts with the help of real time monitoring of earthquakes and identification of the precursory nucleation phase, which leads to successful forecasts. A cascade model for the generation of foreshocks for Koyna-Warna earthquakes has been proposed based on the sequential migration of foreshocks to deeper depths, their similar focal mechanisms, and increase in Coulomb stress values in the foreshock sequence. This model suggests that foreshocks are nucleating at shallow depth and the nucleation zone deepens down to the base of the seismogenic depth to cause the moderate size Koyna-Warna events.

Prasad, Srinivas, Meshram, Singh and Tiwari present co-seismic gravity changes observed in the Koyna-Warna region. Temporal gravity changes recorded by gPhone and GRACE satellite in conjunction with seismological, geodetic (cGPS) observations and groundwater level measurements are correlated with the occurrence of earthquakes. GRACE data suggest that seasonal vertical deformation due to hydrological loading is $\sim 2 \mathrm{~cm}$, which corroborates with continuous GPS observations. Seasonal hydrological loading of the region, which is in a phase of reservoir loading, might be influencing the critically stressed KWR leading to the seasonal seismicity of the region.

Patro, Borah, Ashok Babu, Veeraiah and Sarma have presented results of the Ground Electrical and Electromagnetic (GEE) studies (MT, CSAMT, DRS) carried out in the Koyna-Warna zone since 1976. These studies rule out the presence of sub-trappean sediments in the region. Based on MT studies a well-defined crustal block structure, characterized by high resistive blocks interspersed with moderately conductive features has been inferred. The conductive features correspond well with seismogenic structural features, for e.g., the Konya Fault Zone, the West Coast Fault, and the Donachiwada Fault. The conductive linear features bordering the resistive blocks represent fluid filled fracture/fault zones. It is inferred that because of the NE to NS oriented compressive stress regime in the Indian shield, these structural features may become the locales of stress accumulation which may get released due to fluid filling of these zones under the influence of nearby reservoirs, resulting in RTS.

Reddy, Kumar and Purnachandra Rao present the results of longterm hydro-chemical earthquake precursor studies in Koyna-Warna region. Hydro-chemical and stable isotope signatures in the groundwater from 15 bore wells (depth 100 to $250 \mathrm{~m}$ ) are monitored for over 12 years since January 2005. Cyclic or temporal variation in hydrochemistry is observed in few sensitive wells in Koyna region. The Govare well in Koyna is found to be most sensitive; the observed hydro-chemical cycle is closely associated with local earthquakes of $M>5$. The earthquakes of $M<5$ that occurred either in Warna cluster or close to the observation wells, did not generate hydro-chemical precursory changes. The increase in hydrochemistry is hypothesized as mixing of two aquifer waters with different hydrochemistry. It is noted that a precursory hydro-chemical cycle is observed during first quarter of 2015 , but no earthquake $M>5.0$ occurred till date. The cyclic changes in hydrochemistry, however, indicate an on-going earthquake processes and point out the possibility of an impending earthquake of $\mathrm{M}>5$ in the region.

Hazarika, Yadav and Roy have addressed the influence of 
permeability in modeling RTS at Koyna. Earlier studies have shown that RTS can be explained in terms of stress and pore pressure changes due to poroelastic response of the rock matrix. They employ 2-D finite element models to simulate the evolution of pore pressure up to 5 years after the reservoir impoundment in 1962, using a permeability range from $10^{-16}$ to $10^{-14} \mathrm{~m}^{2}$. A permeability of $10^{-16} \mathrm{~m}^{2}$ does not produce any significant change in pore pressure. A ten-fold increase in permeability produces significant changes up to a depth of $2 \mathrm{~km}$ only beneath the reservoir after 5 years of impoundment. Permeability values between $10^{-15} \mathrm{~m}^{2}$ and $10^{-14} \mathrm{~m}^{2}$ are required to induce critical pore pressure changes in the range of 0.1-1 MPa up to a depth of $10 \mathrm{~km}$ for RTS in a critically stressed region. Studies on core samples of granitic basement rock down to a depth of $1522 \mathrm{~m}$ in the Koyna region provide evidences of fracture zones that may contribute to water channelization causing RTS.

Gahalaut and Gahalaut have reviewed the models and processes suggested for the sustained seismicity in the Koyna-Warna region. They accept the role of the reservoir(s) in triggering earthquakes, and examine prevailing models and hypotheses such as fault interaction, flexure of Western Ghat escarpment, velocity heterogeneity, and earthquakes being considered as aftershocks, but find no explanation for the continued RTS in the region for the past 50 years. They, however, observe that it is possible that all put together and some other unknown additional processes are at work and there is a mish-mash of several processes attending the region, causing continuing seismicity for past five decades.

Jadhav and Kshirsagar have examined geomorphic signatures in parts of Koyna region using satellite images and morphometric indices with limited field checks in key areas for understanding the role of tectonics in this seismically active zone. The Koyna River zone, particularly downstream of Koyna Dam, is characterized by incised narrow valleys, steep escarpments and structurally controlled drainage. Presence of knick points at consistent elevations between $825 \mathrm{~m}$ to $675 \mathrm{~m}$, steep gradients in an otherwise gradual longitudinal profile and valley width to height ratio of less than 1.0 suggest readjustment of the streams along NW-SE and N-S directions. The escarpment slopes in general have en echelon arcuate ridge pattern $\sim \mathrm{N} 45^{\circ}-\mathrm{N} 225^{\circ}$ in the western part, and then becomes $\sim \mathrm{N} 10^{\circ}-\mathrm{N} 190^{\circ}$ near Donachiwadi, almost orthogonal to the E-W Koyna River. The Donachiwada fault runs parallel to the escarpment slopes observed near Kodoli. The fluvial system in Koyna thus indicates rejuvenation controlled by basementpropagated structures.

Duraiswami, Gadpallu, Maskare, Purwant, Meena, Krishnamurthy and Mahabaleshwar present flow mapping and physical volcanology of 15 basaltic lavas in the Koyna-Warna region. Transitional lavas like rubbly pahoehoe are most common morpho-type exposed in these ghat sections. Occurrence of aa and pahoehoe morpho-types in the lava flow sequence is subordinate. Three prominent pahoehoe flows separated by red bole horizons are seen in the upper parts of the Kumbharli ghat. Presence of pahoehoe lavas in the Koyna-Warna region hints at possible hitherto unrecorded southern extension of Bushe-like flow fields. The present study confirms the existence of pahoehoe-slabby-rubbly- aa flow fields and transitions even in the upper echelons of the Deccan Trap stratigraphy. The morphology and internal structure of lava flows exposed at the ghat sections in the Koyna-Warna region could guide subsurface core-logging that is critical in deciphering the physical volcanology and emplacement dynamics of basaltic lava flows penetrated by drill holes under the scientific deep drilling program in the Koyna region.

Bhave, Siddique, Desai, Patil Pillai, Dole, Kulkarni, and Kale note that geophysical investigations in the Koyna-Warna seismic zone have indicated presence of faults in the basement overlain by the thick Deccan Lava pile. However, there is a dearth of unambiguous surface manifestations of such faults, apart from the surface ruptures from the epicentral zone of the December 10, 1967 earthquake. They report an exposed NW-SE trending reverse fault in the Deccan Trap basalts in this region. The discovery of the Sutarwadi Fault shows that the Deccan Trap basalts also have been subjected to faulting and are not structurally 'undisturbed'. It suggests that surface exposures of other similar faults may be present in this region, awaiting documentation. The knowledge of the orientation, sense of movement and distribution of such faults in the Deccan Traps has the potential of providing a better understanding of the fault framework responsible for RTS.

Bhaskar Rao, Sreenivas, Vijaya Kumar, Khadke, Krishna and Babu have subjected two drill core samples from borehole KBH-1 near Rasati to in situ Laser Ablation - Inductively Coupled Plasma Mass Spectrometry (LA-ICPMS) and LA-MC (multi collector)-ICPMS zircon $\mathrm{U}-\mathrm{Pb}$ age and Hf-isotopic composition studies. The KBH-1 basement section comprises of predominantly grey migmatitic gneisses of granodiorite, tonalite and quartz monzodiorite composition apart from minor pink monzogranite. Zircons from a granodiorite and a monzogranite samples yield consistent $\mathrm{U}-\mathrm{Pb}$ ages of $2710 \pm 63 \mathrm{Ma}$ and $2700 \pm 49 \mathrm{Ma}(2 \sigma$ errors $)$. The initial ${ }^{176} \mathrm{Hf} /{ }^{177} \mathrm{Hf}$ values lie in a narrow range $(0.281162$ to 0.281283$)$ corresponding to $\varepsilon_{\mathrm{Hf}(\mathrm{T})}$ values of +3.7 to +8.0 indicating that the magmatic precursors of the KBH-1 gneisses represent juvenile magmatism around $2700 \mathrm{Ma}$. In terms of the composition and age, a correlation between the gneisses in the KBH-1 borehole and the Neoarchean basement gneisses of the Eastern Dharwar Craton (EDC) is emphasized arguing for the extension of the EDC to the Koyna-Warna region.

Sinha, Som and Roy present the megascopic features of $932.5 \mathrm{~m}$ thick pile of lava flows comprising of 30 flows obtained through drilling the Rasati bore-well near the Koyna Dam. This study records the presence of granite wash ( $\sim \mathrm{m}$ thick) over basement and below basalt representing Late Archaean to Cretaceous period hiatus. The megascopic features of the basement rocks, presumably of Late Archaean age have been described. A fair picture of sub-surface preDeccan topography is shown with the help of borehole data, which confirm the nearly flat topography of pre-Deccan surface especially in this part of the area occupied by 30 flows of Deccan basalt. Correlation of 30 flows with the established stratigraphy has also been attempted to address subsurface existence of Ambenali (Upper) and Poladpur Formations of Wai Subgroup in Koyna-Warna area.

Sangode, Venkateshwarulu, Mahajan and Randive report magnetic - mineralogical variability in the $1248 \mathrm{~m}$ long core obtained from borehole \#KBH 07 located at $17^{\circ} 18^{\prime} 07^{\prime \prime} \mathrm{N}, 73^{\circ} 47^{\prime} 28.2^{\prime \prime} \mathrm{E}$. The top of the borehole is at $960 \mathrm{~m}$ above the mean sea level. The entire core was sampled at $\sim 10 \mathrm{~m}$ intervals for magnetic mineralogical studies. Analysis of routine rock magnetic parameters depicted significant higher order temporal variations. The giant plagioclase lath bearing (GPB) horizons show highest variability of ferromagnetic concentration marked by anomalous peaks. Overall, the variability of rock magnetic parameters, independent of lava flow units, suggest that the changeover in magnetic mineral concentration, composition and domain size occur at major episodes in magma composition. The authors conclude that the complex variation in rock magnetic parameters independent of flow units reflect temporal magnitudes of compositional variability, cooling and emplacement history that needs detailed petro-mineralogical studies.

Misra, Bartakke, Athavale, Vyasulu, Goswami and Roy presented the petrological characteristics and micro-structures of the basement using the cores from 4 deep bore wells KBH-1 (Rasati) in the north, KBH-5 (Phansawale) in the west, KBH-6 (Ukhalu) and KBH-7 (Panchgani) in the east, of the Koyna-Warna seismic zone. These boreholes penetrate the entire pile of Deccan basalt and pass through a few hundred meters of the granitic basement. Major findings include: the basement granitoids being dominantly composed of granite-gneiss, granite and migmatitic gneiss; petrology and micro-structure studies 
confirm the occurrence of strained quartz and unstrained plagioclase feldspars in the basement granitoids; localized fault zones within the basement section are characterized by fault breccia, fault gouge, slicken lines with slickensides and pseudo-tachylite; and anastomosing fracture network within these fault zones are good pathways for water channelization, which is supported by abundances of ferruginous and siliceous secondary precipitations following the fractures.

Goswami, Vyasulu, Singh, Shalivahan and Roy have measured rock strength and elastic properties of basement granitoids using 20 core samples from KBH-7 borehole located close to the Donachiwada fault that hosted the 1967 M 6.3 and several M $\sim 5$ earthquakes in the Koyna region. Specimens of granite, granite-gneiss and migmatitic gneiss were tested in the laboratory under dry state and room temperature. The granitoids are characterized by variable compressive strength in the range 22-98 MPa. Stress-strain response of the basement rock indicates varying degrees of deformation even for the same rock type. Young's modulus and Poisson's ratio of the granitoids, computed from the linear elastic portion of the stress-strain curves, vary in the range 8-23 GPa and 0.1-0.3 respectively. The Koyna granitoids are found to have low and variable rock strength compared to granitic rocks from aseismic areas.

Mishra, Misra, Vyas, Nikalje, Warhade and Roy write about $1251 \mathrm{~m}$ long flood basalt core obtained from the $1500 \mathrm{~m}$ deep KBH-7 Panchgani borehole in Panchgani village of Patan sub-division. Fortysix lava flows, starting with the first flow overlying the granitic basement in the region, have been identified through mesoscopic studies of cores. The thickness of Deccan trap in the Panchgani area is $1251.20 \mathrm{~m}$, comprising a succession of 40 simple lava flows and 6 compound lava flows. The contact with the underlying granitic basement occurs over a short span of $90 \mathrm{~cm}$. Infra-trappean sediments are absent. Overall, $\sim 74 \%$ of the basaltic pile is constituted of massive basalt and $\sim 24 \%$ vesicular/amygdaloidal basalt. Red bole horizons are observed in 8 flows. Nine giant plagioclase basalt (GPB) flows are identified in the single vertical section.

Tiwari, Mishra, Srihariprasad, Vyas, Warhade, Nikalje, Bartakke, Mahesh, Pallavi and Roy report that a high-resolution, optical core scan laboratory has been established at Borehole Geophysics Research Laboratory (BGRL) at Karad. The facility provides a DMT CoreScan3 optical core scanner and digital drill core data management system for core logging and analysis. 360 mode high-resolution core-images are produced for detailed unwrapped full circumference of drill core or plane mode for top surface image of slabbed drill core. Planar images of fractured cores and cuttings are also obtained. Image resolution ranges from 5 pix/mm ( 16 megapixel equivalent) to $40 \mathrm{pix} / \mathrm{mm}$ ( 1024 megapixel equivalent) for mapping of ultra high-resolution data. The scanned core images are combined to create a digital core library.

Shashidhar, Mallika, Mahato, Maity and Satyanarayana present results from recent seismic activity in the Koyna-Warna region based on the observations from 6 borehole seismic stations and 23 surface broad band stations. During the period January 2016 to May 2017 a total of 2478 earthquakes in the magnitude range of $m-0.8$ to 3.7 have been recorded. The seismicity is mostly concentrated in the vicinity of the Donachiwada fault and Warna during January - May, whereas it spreads during June - December. ' $b$ ' values have been estimated and found to be varying from 0.74 to 0.93 . Seismicity continues to be present in the identified block where the pilot borehole has been drilled.

Anuradha and Mallika present correspondence between reservoir loading parameters of the Koyna Dam and the RTS. The rate of loading, highest water levels reached, duration of retention of high water levels and whether the previous water maxima has been exceeded or not, influence RTS in the vicinity of Koyna and Warna reservoirs. They have made an update of these parameters till 2016. They also provide a diagram showing the annual number of $M \geq 4$ earthquakes. There is a general trend in decrease of such events over the 5 decades. With 28 such earthquakes during 1967/1968, the number has gradually decreased. The last such event occurred in June 2017 after a gap of 5 years, the previous such earthquake having occurred in 2012 .

The 25 articles included in this issue provide in-depth information about the work that has been carried out on different aspects of RTS at Koyna. A lot of data have been generated. All these data need to be integrated for developing acceptable hypotheses and its confirmation through the ongoing observations and experiments planned to address the genesis of RTS at Koyna.

A post-operation ICDP Workshop to discuss the just completed Pilot Borehole was held at Pune during 14 to 16 October, 2017 to review the work carried out and provide inputs for the proposed Scientific Deep Borehole Laboratory. The Workshop was attended by $\sim 60$ participants, including 20 from outside India. There was an overall satisfaction and appreciation of the work carried out so far. The Koyna Project has been named as the "Light House Project of ICDP". One major issue and area of focused effort is to better define the Donachiwada Fault, so that the main borehole could be drilled in the immediate vicinity of the fault and at a depth of $4 \mathrm{~km}$ or so, could be bent to intersect the fault. This would make it possible to study physical and chemical changes in the fault zone before, during and after the occurrence of the target earthquake(s). The field investigations and the earthquakes located with the additional input from the six borehole seismometers has narrowed down the width of the Donachiwada Fault to $\sim 1 \mathrm{~km}$. To better define the Donachiwada Fault, operation of additional borehole seismometers and a string of seismometers in a vertical hole are of utmost importance.

There are concerns as to how long RTS may continue at Koyna. Over the years, there has been a general decrease in RTS events at Koyna. However, as shown by Shashidhar et al. (this issue), in the immediate vicinity of the $3 \mathrm{~km}$ deep Pilot Borehole that was just completed in Koyna, during the period January 2016 through $15^{\text {th }}$ May 2017, twenty-eight earthquakes of M 2.0 to 2.9 and 5 earthquakes of M 3.0 to 3.7 occurred. The target of setting up of the Deep Borehole Laboratory is to study M 2 and larger earthquakes in near field. This shall be met.

I wish to thank the Council of the Geological Society of India, particularly Dr. B. Mahabaleshwar, Editor of the Journal, for his enthusiastic support to dedicate the December 2017 issue to 50 years of the 10 December, 1967 M 6.3 Koyna earthquake. Shri B.R. Krishna, Managing Editor of the Journal, deserves a special mention for his help in coordinating the preparation of this issue. It is a pleasure to acknowledge all the authors for meeting a very stringent time line and sticking to the length of the articles as requested. The timely examination of the manuscripts by the reviewers: Drs. B.R. Arora, J.R. Kayal, D. Sarkar, K.V. Subbarao, T. Radhakrishna, V. Balaram, Amalendu Sinha, Manoj Mukhopadhya, R.K. Chadha, Fareeduddin, Saibal Gupta, D.K. Sinha, and N.J. Pawar is acknowledged. At NGRI, M. Uma Anuradha and K. Mallika helped in the processing of the manuscripts.

NGRI scientists worked enthusiastically all these fifty years on Koyna related studies. From 2005 onwards Ministry of Earth Sciences provided support to Koyna projects.

HARSH K. GUPTA

October 24, 2017 